\title{
The Journey of Primary Care Practices to Meaningful Use: A Colorado Beacon Consortium Study
}

\author{
Douglas H. Fernald, MA, Robyn Wearner, RD, and W. Perry Dickinson, MD
}

Background: The Health Information Technology for Economic and Clinical Health Act of 2009 provides for incentive payments through Medicare and Medicaid for clinicians who implement electronic health records (EHRs) and use this technology meaningfully to improve patient care. There are few comprehensive descriptions of how primary care practices achieve the meaningful use of clinical data, including the formal stage 1 meaningful use requirements.

Methods: Evaluation of the Colorado Beacon Consortium project included iterative qualitative analysis of practice narratives, provider and staff interviews, and separate focus groups with quality improvement (QI) advisors and staff from the regional health information exchange (HIE).

Results: Most practices described significant realignment of practice priorities and aims, which often required substantial education and training of physicians and staff. Re-engineering office processes, data collection protocols, EHRs, staff roles, and practice culture comprised the primary effort and commitment to attest to stage 1 meaningful use and subsequent meaningful use of clinical data. While realizing important benefits, practices bore a significant burden in learning the true capabilities of their EHRs with little effective support from vendors. Attestation was an important initial milestone in the process, but practices faced substantial ongoing work to use their data meaningfully for patient care and QI. Key resources were instrumental to these practices: local technical EHR expertise; collaborative learning mechanisms; and regular contact and support from QI advisors.

Conclusion: Meeting the stage 1 requirements for incentives under Medicare and Medicaid meaningful use criteria is the first waypoint in a longer journey by primary care practices to the meaningful use of electronic data to continuously improve the care and health of their patients. The intensive re-engineering effort for stage 1 yielded practice changes consistent with larger practice aims and goals. While many of these practices are now poised to use data meaningfully, faster progress will likely come with continued local QI and technical support and planned community-wide learning. (J Am Board Fam Med 2013;26:603-611.)

Keywords: Electronic Medical Records, Health Information Technology, Meaningful Use, Primary Health Care, Quality Improvement

As part of the American Recovery and Reinvestment Act of 2009, the Health Information Tech-

This article was externally peer reviewed.

Submitted 20 December 2012; revised 10 June 2013; accepted 18 June 2013.

From the Department of Family Medicine, University of Colorado School of Medicine, Aurora.

Funding: Funding for this effort was provided by the Office of the National Coordinator for Health Information Technology, Department of Health and Human Services.

Conflict of interest: none declared.

Corresponding author: Douglas Fernald, MA, Department of Family Medicine, University of Colorado School of Medicine, 12631 East 17th Avenue, Mail Stop F496, Aurora, CO 80045 (E-mail: Doug.fernald@ucdenver.edu). nology for Economic and Clinical Health Act provided for incentive payments through the Centers for Medicare and Medicaid Services (CMS) for clinicians who use electronic health records (EHRs) according to meaningful use criteria. ${ }^{1}$ Practices often have struggled with the implementation of EHRs, focusing primarily on documentation to justify payment. ${ }^{2,3}$ Beyond documentation, EHRs are new information management systems that can potentially transform the delivery of patient care, providing the necessary data for such things as pointof-care decision support, population management, care management, and quality improvement (QI) ac- 
tivities. However, the additional burden of achieving meaningful use, while necessary to achieve the full realization of benefits of the patient-centered medical home model, has been a challenge for practices. ${ }^{4}$ Stage 1 of the CMS EHR incentive program was intended to establish a baseline for capturing electronic data and sharing information. Providers seeking the incentive offered in stage 1 had to demonstrate meaningful use of their EHR by meeting all 15 core objectives, their choice of 5 of the 10 menu objectives, and a minimum of 6 clinical quality measures (Table 1$){ }^{5}$

A 2011 nationally representative survey of physicians found that while $51 \%$ of providers intended to apply for meaningful use incentives, just $11 \%$ reported having computerized capabilities to support at least 10 of the 15 core objectives for stage 1 incentives. ${ }^{6}$ A systematic review of health information technology (IT) in practices noted significant barriers to the adoption of health IT while advocating for better understanding of the barriers to effective implementation after adoption of health IT. ${ }^{7}$ Barriers to adoption include concerns about costs, insufficient training, practice culture, current technical limitations, and concerns that existing EHR systems do not meet the clinical needs of practices. Smaller practices in particular are more likely to have concerns about the costs associated with acquiring and integrating EHRs and that their system will become obsolete. ${ }^{8}$

Recognizing these problems, the Office of the National Coordinator for Health Information Technology funded 60 health IT regional extension centers (RECs) to assist clinicians in adopting and meaningfully using EHRs. ${ }^{9}$ In addition, the Office of the National Coordinator for Health Information Technology developed the Beacon Community Cooperative Agreement Program, which provides funding to support 17 communities in building and strengthening their health IT infrastructure and exchange capabilities to improve care coordination, increase the quality of care, and slow the growth of health care spending. ${ }^{10}$

The Colorado Beacon Consortium (CBC), one of the 17 Beacon communities, aimed to demonstrate how costs can be reduced and patient care and population health improved through the collection, analysis, and sharing of clinical data and the redesign of primary care practices and clinics. ${ }^{11}$ Although attestation for stage 1 meaningful use was an aim of the $\mathrm{CBC}$, the consortium had goals be-
Table 1. Stage 1 Meaningful Use Core and Menu Objectives by Domain ${ }^{5}$

\begin{tabular}{|c|c|}
\hline Core objectives* & \\
\hline \multirow[t]{11}{*}{$\begin{array}{l}\text { Improve quality, safety, } \\
\text { efficiency }\end{array}$} & $\begin{array}{l}\text { Use computerized provider order } \\
\text { entry for medication orders }\end{array}$ \\
\hline & $\begin{array}{l}\text { Implement drug interaction } \\
\text { checks }\end{array}$ \\
\hline & Maintain up-to-date problem list \\
\hline & $\begin{array}{l}\text { Generate and transmit } \\
\text { prescriptions electronically }\end{array}$ \\
\hline & Maintain active medication list \\
\hline & $\begin{array}{l}\text { Maintain active medication } \\
\text { allergy list }\end{array}$ \\
\hline & Record demographics \\
\hline & Record vital signs \\
\hline & Record smoking status \\
\hline & $\begin{array}{l}\text { Report ambulatory clinical } \\
\text { quality measures }\end{array}$ \\
\hline & $\begin{array}{l}\text { Implement one clinical decision } \\
\text { support rule }\end{array}$ \\
\hline \multirow[t]{2}{*}{$\begin{array}{l}\text { Engage patients and } \\
\text { families }\end{array}$} & $\begin{array}{l}\text { Provide patients with electronic } \\
\text { copy of health information }\end{array}$ \\
\hline & $\begin{array}{l}\text { Provide clinical summaries for } \\
\text { patients }\end{array}$ \\
\hline $\begin{array}{l}\text { Improve care } \\
\text { coordination }\end{array}$ & $\begin{array}{l}\text { Capability to exchange key } \\
\text { clinical information }\end{array}$ \\
\hline $\begin{array}{l}\text { Ensure privacy and } \\
\text { security for personal } \\
\text { health information }\end{array}$ & $\begin{array}{l}\text { Protect electronic health } \\
\text { information }\end{array}$ \\
\hline \multicolumn{2}{|l|}{ Menu objectives ${ }^{\dagger}$} \\
\hline \multirow[t]{4}{*}{$\begin{array}{l}\text { Improve quality, safety, } \\
\text { efficiency }\end{array}$} & $\begin{array}{l}\text { Implement drug formulary } \\
\text { checks }\end{array}$ \\
\hline & $\begin{array}{l}\text { Incorporate clinical lab test } \\
\text { results as structured data in } \\
\text { EHR }\end{array}$ \\
\hline & $\begin{array}{l}\text { Generate patient list by specific } \\
\text { condition }\end{array}$ \\
\hline & Send reminders to patients \\
\hline \multirow[t]{2}{*}{$\begin{array}{l}\text { Engage patients and } \\
\text { families }\end{array}$} & $\begin{array}{l}\text { Provide patients with timely } \\
\text { electronic access }\end{array}$ \\
\hline & $\begin{array}{l}\text { Identify patient-specific } \\
\text { education resources }\end{array}$ \\
\hline \multirow[t]{2}{*}{$\begin{array}{l}\text { Improve care } \\
\text { coordination }\end{array}$} & $\begin{array}{l}\text { Perform medication } \\
\text { reconciliation for care } \\
\text { transitions }\end{array}$ \\
\hline & $\begin{array}{l}\text { Provide summary care record for } \\
\text { care transitions and referrals }\end{array}$ \\
\hline \multirow[t]{2}{*}{ Public health } & $\begin{array}{l}\text { Capability to submit data to } \\
\text { immunization registries or } \\
\text { information systems }\end{array}$ \\
\hline & $\begin{array}{l}\text { Capability to submit electronic } \\
\text { syndromic surveillance data to } \\
\text { public health agencies }\end{array}$ \\
\hline
\end{tabular}

${ }^{*}$ Must complete all 15.

${ }^{\dagger}$ Must complete 5; at least 1 must be a public health measure.

yond the formal CMS core and menu objectives to more broadly demonstrate how costs could be reduced and patient care and the general health of the 
Table 2. Brief Descriptions of Qualitative Data Sources

\begin{tabular}{|c|c|c|}
\hline Data source & Description & Participants \\
\hline Practice narratives & $\begin{array}{l}\text { Open-ended responses to structured questions; } \\
\text { completed by practice personnel (staff or } \\
\text { providers) }\end{array}$ & $\begin{array}{l}51 \text { practices (39 family medicine, } 7 \text { general } \\
\text { internal medicine, } 5 \text { general pediatrics) }\end{array}$ \\
\hline $\begin{array}{l}\text { QI advisors focus group } \\
\text { discussion }\end{array}$ & $\begin{array}{l}\text { Semistructured focus group discussion; facilitated by } \\
\text { the evaluation team; in person }\end{array}$ & $\begin{array}{l}1 \text { group discussion (all } 5 \text { QI advisors plus } 1 \\
\text { technical analyst) }\end{array}$ \\
\hline $\begin{array}{l}\text { REC focus group } \\
\text { discussion }\end{array}$ & $\begin{array}{l}\text { Semistructured focus group discussion; facilitated by } \\
\text { the evaluation team; by teleconference }\end{array}$ & $\begin{array}{l}1 \text { group discussion with REC staff/leadership (6 } \\
\text { staff from the REC, including executive staff) }\end{array}$ \\
\hline $\begin{array}{l}\text { Provider and staff } \\
\text { interviews }\end{array}$ & $\begin{array}{l}\text { Semistructured individual or paired interviews; } \\
\text { facilitated by the evaluation team; by } \\
\text { teleconference or in person }\end{array}$ & $\begin{array}{l}13 \text { interviews (9 family medicine, } 2 \text { general } \\
\text { internal medicine, } 2 \text { general pediatrics; } \\
\text { included } 7 \text { providers, } 9 \text { staff overall; } 3 \\
\text { interviews included both) }\end{array}$ \\
\hline
\end{tabular}

REC, regional extension center; QI, quality improvement.

population could be improved. As an important part of its work, the CBC deployed QI advisors and health IT experts to assist practices in using data meaningfully in patient care and QI. The purpose of this article is to describe the journey, struggles, successes, and barriers to obtaining and meaningfully using electronic clinical data for QI in primary care practices participating in the $\mathrm{CBC}$ and to inform future work by other primary care practices seeking to meaningfully use electronic clinical data.

\section{Methods}

The Practice Innovation Program at the Department of Family Medicine at the University of Colorado School of Medicine worked with the CBC to develop focused evaluation questions and processes relevant to Colorado's Beacon program. The evaluation was reviewed for the protection of human subjects and was approved by the Colorado Multiple Institutional Review Board.

\section{Practice Participation}

The CBC region included approximately 112 primary care practices spread across 7 counties in western Colorado. Practices choosing to participate in the CBC were the primary subjects, which included 51 mostly small to intermediate-sized community-based primary care practices in rural or urban settings. Among these practices, 39 were family medicine, 7 were general internal medicine, and 5 were general pediatrics. Participating practices received (1) technical support for EHR implementation, registry implementation, extraction of quality measurement data, and other meaningful use activities through the regional health information exchange (HIE), the health IT REC, and CBC technical analysts; (2) practice improvement assistance from QI advisors deployed by the CBC for practice redesign and QI efforts centered around meaningful use attestation and the subsequent use of clinical data in patient care and QI; (3) quarterly collaborative learning sessions bringing representatives from the practices together for training and to share experiences; and (4) incentive payments of up to $\$ 10,000$. Among the 51 practices, 18 different EHRs were represented. Three practices had no EHR at the time of this analysis.

\section{Data Sources}

The evaluation relied on multiple sources of qualitative data: practice narratives, focus groups, and individual interviews (Table 2). Each practice completed a structured, monthly narrative report that documented practice changes, challenges, plans, and achievements arising from their participation in the Beacon collaborative and their work to meaningfully use data. Practices reported data that covered their entire period of participation in the Beacon initiative; however, because practices were enrolled in cohorts, not all practices had completed final reports at the time of our analysis. Data for this report were collected between January 2011 and September 2012.

Based on an initial analysis of practice narratives, gaps in the available data were identified and used to develop a set of key questions for separate focus groups with the QI advisors and the HIE/REC provider. These focus groups elicited additional detailed information about their work with practices around meaningful use, including the role of QI advisors in assisting practices, important successes and barriers, and recommendations for other 
practices. The QI advisors also helped determine which practices to interview for the specific data objectives during the last phase of data collection.

Finally, a sample of 13 practices was chosen for interviews to learn from practices with a range experiences and settings, including practices that successfully obtained, reported, and used quality measurement data and those that struggled as well as practices that were at different stages of their involvement in the Beacon initiative. Practices also were chosen from different primary care disciplines and from each of the 4 cohorts. All but one of the selected practices had completed the year-long Beacon program. Because clinicians and staff members play key roles in practice redesign, both were interviewed about their experiences in obtaining and meaningfully using data. The interviews asked about the practice's path toward meaningfully using data, including preparation, barriers, and successes along the way; how they use data meaningfully for patient care; and recommendations for other primary care practices. Interviews and discussions were audio-recorded, and verbatim transcripts were used for the analysis. (Summary interview questions for each data source are in the online Appendix 1.)

\section{Qualitative Analysis}

Data were reviewed and collected in stages to facilitate focused data collection in each subsequent phase. The investigators engaged in an iterative qualitative analysis process involving cycles of reading, summarizing, and re-reading the data.

All practice narratives were first coded to develop a practice perspective on barriers, successes, and support strategies used to obtain and meaningfully use data for the practices' clinical and QI work. Questions for further data collection also were generated to inform the development of the focus group discussion guide. Analysis of focus group data helped to identify specific domains and questions for interviews with providers and staff in a purposive sample of $\mathrm{CBC}$ practices.

Two team members (DHF, RW) immersed themselves in the data to identify provisional themes for presentation and discussion by the team lead (WPD) and the CBC QI director. The team used a template coding style ${ }^{12}$ to efficiently segment data with a priori codes (based on literature review and project objectives) while also allowing for the emergence of new conceptual codes. The segmented data subsequently were organized into broader conceptual categories for further review and coding. This process was used for each data source, arriving at a final assessment and report of major and minor themes that describe the journey, struggles, and successes related to meaningfully using clinical data. ATLAS.ti (version 6; Scientific Software Development, GmbH, Berlin, Germany) was used to manage, code, and retrieve data during analysis.

Using the summary reports, a meta-matrix of themes was organized into major analytical constructs and sorted by data source. ${ }^{13}$ Data in the matrix were successively reviewed and refined to arrive at a summary table and a synthesis of crossdata results.

\section{Results}

Across data sources, providers, staff, Beacon support staff, and HIE staff consistently identified major themes along the path toward meaningful use of clinical data into generally (although not always) sequential major constructs: getting started, re-engineering, attestation, and using data meaningfully (Table 3), with additional themes regarding support and recommendations for other primary care practices.

Overall, the major themes were observed consistently across practices types and respondent types, although they were not necessarily experienced equally in each practice. We describe the major themes in each construct below, with illustrative quotes set in italics.

\section{Getting Started}

Leadership alignment was a crucial element early in a practice's journey toward meaningful use of data. Most practices believed that many of the changes being promoted aligned with the direction they wanted to take their practices anyway, although pediatric practices pointed out that the meaningful use measures were less relevant to the pediatric patient population. It was important that practices understood that this was not "just another project," but rather a path to a new way of doing business, with a focus on providing better patient care. Communication and training for both EHR functionality and practice improvement were essential to foster buy-in from leadership and staff and tailor support for change efforts. "It was the concept of, look, 
Table 3. Major Thematic Constructs with Examples of Barriers, Successes, and Resources That Support Practices in Their Journey to Meaningful Use Data

\begin{tabular}{|c|c|c|c|}
\hline & Barriers & Successes & Support Resources \\
\hline Getting Started & $\begin{array}{l}\text { Provider and staff resistance to } \\
\text { change } \\
\text { Lack of personal connection to } \\
\text { meaningful use changes } \\
\text { Technical insufficiency of } \\
\text { EHR* }^{*}\end{array}$ & $\begin{array}{l}\text { Staff and provider buy-in } \\
\text { Staff and provider turnover } \\
\text { Alignment of practice vision with } \\
\text { vision of meaningful use }\end{array}$ & $\begin{array}{l}\text { Learning collaboratives } \\
\text { On-site advising, education, and } \\
\text { training } \\
\text { Network of local/regional peers }\end{array}$ \\
\hline Re-engineering & $\begin{array}{l}\text { EHR: cost, technical } \\
\text { limitations, upgrades, new } \\
\text { installations (especially } \\
\text { among "certified" EHRs) } \\
\text { EHR vendor support } \\
\text { Data quality and accuracy } \\
\text { Insufficient office processes } \\
\text { Inconsistent use of EHR } \\
\text { Time-consuming and tedious } \\
\text { Staff role changes }\end{array}$ & $\begin{array}{l}\text { Technical support and } \\
\text { troubleshooting } \\
\text { Improved office processes and } \\
\text { efficiency } \\
\text { Improved consistency of EHR } \\
\text { use } \\
\text { Accurate data and reports } \\
\text { QI tools and processes (eg, } \\
\text { PDSAs, process maps, regular } \\
\text { meetings, communication) } \\
\text { Culture change } \\
\text { Staff engagement } \\
\text { Stronger sense of community } \\
\text { among practices }\end{array}$ & $\begin{array}{l}\text { QI advisors } \\
\text { Health IT REC } \\
\text { Training } \\
\text { Learning collaboratives } \\
\text { Peers } \\
\text { Local technical support and } \\
\quad \text { expertise }\end{array}$ \\
\hline Attestation & $\begin{array}{l}\text { Inflexible meaningful use } \\
\text { criteria }\end{array}$ & $\begin{array}{l}\text { Successful attestation of stage } 1 \\
\text { meaningful use }\end{array}$ & $\begin{array}{l}\text { QI advisors } \\
\text { Health IT REC } \\
\text { Technical support }\end{array}$ \\
\hline $\begin{array}{l}\text { Using Data } \\
\text { Meaningfully }\end{array}$ & $\begin{array}{l}\text { Availability of time and } \\
\text { resources } \\
\text { EHR upgrades, insufficiency } \\
\quad \text { (especially for stages } 2 \text { and } 3 \text { ) } \\
\text { EHR vendor support } \\
\text { Fatigue } \\
\text { Continued staff or provider } \\
\text { resistance } \\
\text { Patient activation and } \\
\text { participation } \\
\text { Lack of shared vision or } \\
\text { understanding }\end{array}$ & $\begin{array}{l}\text { Registries } \\
\text { Population management } \\
\text { Routine use of data } \\
\text { Patient portals } \\
\text { Medication reconciliation } \\
\text { New patient services } \\
\text { Patient feedback } \\
\text { Automated patient follow-up }\end{array}$ & $\begin{array}{l}\text { Local technical support and } \\
\text { expertise } \\
\text { Learning collaboratives } \\
\text { QI advisors (resources, connections, } \\
\text { accountability, research, cross- } \\
\text { practice sharing) } \\
\text { Network of peers/collaborators }\end{array}$ \\
\hline
\end{tabular}

EHR, electronic health record; IT, information technology; PDSA, plan-do-study-act learning cycle; QI, quality improvement; REC, regional extension center.

you're going to bave to do more, but the primary outcome is better bealth and better patient care and just doing our jobs really, really well."

Although many practices viewed meaningful use changes as part of the work they were already doing, others anticipated and experienced significant and disruptive changes. In a few cases, the cultural change and new practice orientation toward adaptive learning and change led to staff turnover. Staff turnover, while disruptive, had productive outcomes by bringing in new staff with skills and interests better aligned to the work needed to achieve meaningful use. "I think we are all now more efficient than we were, but the process was a steep learning curve. It was very frustrating. It took a lot of time and there's still a doc or two who have probably moved up their retirement plan."

\section{Re-engineering}

Before practices could reliably capture and use electronic patient data, practices described notable and necessary re-engineering of their offices. Practices created new data collection and data entry protocols, modified EHR templates and shortcuts, defined new staff roles, rearranged patient flow, and worked on developing a practice culture that supported ongoing capture and use of EHR data for patient care. For example, documenting smoking status for future reporting could require developing a new data collection procedure to ensure 
every patient is asked and that the response is consistently recorded in the same location in the EHR. Developing reports on smoking status documentation then required developing complex data queries that retrieve specific patient records (eg, specific ages, providers, and date ranges) to meet reporting criteria.

Practices reported and discussed intensive work with providers, staff, and support resources, using rapid cycle tests of change to implement workflow changes to better capture and report patient data. Assembling the right team-usually the practice manager, a clinician, and staff members-to plan and implement this work was essential. "We have put a team together that involves every area of the practice that will encourage positive changes in areas that need help to be more efficient and focus on patient care."

While most practices struggled to obtain the necessary data from their EHRs and needed external assistance, during this re-engineering phase, practices learned at a deeper level about the capabilities and limits of their EHR. Unfortunately, each practice bore the burden of this learning because EHR vendors were of limited help, with some practices experiencing unstable software, unexpected costs for technical support, slow response times, incomplete or inaccurate responses, and delayed or failed upgrades. The additional costs and staff resources of EHR systems, upgrades, and IT support services added frustration. "Getting started, there were definitely frustrations around not being able to gather the data we needed out of the [EHR] system and knowing the data we would pull was not necessarily accurate and would have to be validated."

A few notable benefits from re-engineering offset some of the frustrations and burden on practice resources. Consistency in processes and documentation was a commonly noted benefit, yielding better data and more accurate reports or registries. The effort to improve data through careful tracking, review, revisions, and retesting allowed practices the opportunity to review and assess their clinical data in various areas over time. The data often provided motivation for further change. When practices saw accurate data regarding their performance, it spurred them to move forward to improve their care processes. "The importance of using this information . . . and discussing this with patients at their visits. So many times info is taken but not always utilized in care of patients. The communica- tion on the measure at team meetings allowed the entire team to understand what information needed to be collected. We also worked on workflow around each measure."

\section{Attestation}

While practices generally shared a sense of accomplishment when they formally attested that they met the criteria of stage 1 meaningful use, there was not much discussion around this as a major event. Several practices acknowledged that stage 1 was not the end of their work. However, for a few practices that did not have full buy-in from all physicians and staff, attestation seemed to signal that the strain of meeting stage 1 requirements was over and that the practice could return to business as usual. In those practices, achievement of attesting to meaningful use was perceived as the end goal instead of part of the ongoing process of improving care through the meaningful use of data.

\section{Meaningfully Using Data}

Once practices' processes and systems were reengineered and practices had attained the goal of attestation, practices looked beyond "checking boxes" to meet meaningful use criteria and moved into a phase of trying to really use the data meaningfully in their QI and clinical activities. Collectively, providers and staff mentioned several ways they were using their data meaningfully, including:

- tracking reports to prevent certain patients from "slipping through the cracks" by bringing those patients in for needed follow-up that they might otherwise miss;

- registries for population management;

- data reporting and data reviews to support practice improvement agendas;

- referral and recall systems that track and report lab, radiograph, and consultation reports;

- patient visit summaries, which provided patients with important information from their visit and kept practices and patients up to date with demographic information; and

- portals for scheduling appointments and providing patient summaries, which patients could access between visits.

Several practices, however, noted that they had not yet begun to meaningfully use their data, and most practices realized that they had just begun to mean- 
ingfully use their data, having set up the structure for continued QI work. "We are doing things that we weren't doing just a couple years ago in terms of population management. We are now doing it as part of [a] routine, doing our registry reports and looking at the registry reports on a monthly basis and developing some strategies to improve the outcome measures that we're working on."

\section{Next Stages}

The transition from attestation to continued use of data required practices to recommit attention and effort to improving their office processes, and in some cases we observed practices facing change fatigue. As one physician put it, "We're sort of obliged in our relationship with Beacon to keep working, and I think that's really been helpful, because it's easy to be like, 'I'm tired."' This coincided with anticipation and concerns for the stage 2 and 3 meaningful use criteria and seemed to be a time where momentum was lost. Several physicians commented on the vision for later stages, seeing stage 1 as a building block and knowing that as meaningful use progresses they will be able to use a fully integrated system of data for patient care. "I suspect that the intent is that all the measures are going to have significant impact and it's more of a building process where we're going to be building on these stage 1 measures and stage 2 and stage 3, such that by stage 3, certainly there's going to be major impacts on patient care."

Concerns about next stages were largely related to EHR limitations. Practices were concerned that extensive EHR upgrades (or a completely new EHR) would be necessary to provide the required data for future meaningful use. They expressed concern that if they had to upgrade or change to a new platform, they would have to essentially start over again with much of the re-engineering work (eg, creating new data entry forms, revising data capture work flows, or providing new training to staff and providers).

\section{Necessary Support Resources}

The need for external resources was echoed by all providers and staff in the CBC practices. They indicated that tailored technical support was imperative to their efforts to meaningfully use clinical data for patient care. The CBC provided the primary support for practices, delivering timely, essential support in the form of education, training, research, technical support, and sharing of promising practices or solutions developed in other practices. This includes an overview of what meaningful use means to a practice, a practice-specific review of EHR data and reporting capabilities, review of EHR reports, EHR-specific training for capturing and reporting data, and researching tools or methods related to meaningfully using data (eg, using registries, patient portals).

CBC QI advisors and technical analysts tailored their work to fit each unique practice and its capacities, including decisions to expedite or slow down work related to meaningful use. This tailoring of the approach to fit with individual practice conditions was thought to be a critical feature of the support.

Several practices noted that an essential role of the CBC QI advisors was encouraging accountability through polite but persistent nudging that kept meaningful use re-engineering and QI in the forefront. On the technical side, CBC provided timely, effective problem-solving for specific EHRs, such as locating discrete data fields, mapping data for report generation, building correct data queries, finding and implementing registry functions, and troubleshooting directly with EHR vendors. The regional HIE also provided direct access to technical expertise on EHRs. "Physicians by themselves are not going to be able to transition to the new care systems that we are not only being asked to do, but that we should be motivated to do to improve our level of care to the patient. So we need coaching. We need accountability. We need support systems to make this happen."

At the community level, the CBC effectively brokered interactions to promote efficient sharing of ideas and solutions among similar practices and foster a stronger sense of community among local providers. Collaborative learning sessions were highly regarded as effective. All data sources pointed to the need for future, ongoing technical support as EHRs continue to be upgraded and replaced and as new demands are placed on them (eg, patient portals, new report requirements, clinical decision support, bidirectional information exchange).

\section{Recommendations from Practices}

The key informants from the practices provided recommendations for other practices embarking on the journey to meaningfully use data (Table 4). 
Table 4. Key Informant Recommendations for Practices Preparing for Meaningful Use

1. Realize that your practice is not just "checking boxes" for meaningful use attestation; you are really changing the way you provide health care.

2. Find and use any knowledgeable sources of local support. Ask a lot of questions and know that you're not the only one out there with questions. Talk with other practices. Learn from others, but use what fits with your style and your practice.

3. Set realistic expectations regarding this work and your progress. Work on small chunks one step at a time.

4. Keep focused on the bigger picture of improving patient care and how everyone's work contributes to that bigger picture.

5. Get your baseline data in order before thinking about how you're going to make improvements in the data.

6. Make the best attempt to choose an EHR that can address what you need it to do. Then take the time to fully understand the capabilities of your EHR.

7. Get your staff involved and engaged in the process. Find the incentive that motivates your providers and staff. Meet regularly with staff and providers to get input and feedback on changes and promote regular communication.

8. Help your physicians and staff to become better users of their EHR. Provide them with training.

9. Understand the measures and what's being asked of you. Get consensus among your providers on which measures are important to focus on and then stick with them. Then take time to understand your data and display your data and reports for all providers and staff in your practice to see.

10. Understand the costs associated with using EHR data effectively.

EHR, electronic health record.

\section{Discussion}

While most providers and administrators in our sample of practices agreed with the overall vision and purpose of meaningful use of EHRs, they also were burdened with the substantial — and at times tedious-tasks of re-engineering their offices to sufficiently meet the requirements of stage 1 attestation. The primary frustrations seemed to relate to EHRs that were limited in their capabilities for providing the necessary electronic patient data and EHR vendors that offered limited assistance.

Despite frustrations and limitations, practices benefited from their intensive re-engineering work: more consistent office processes; better data and reporting; capacity for continued QI work; early advances in efficient population-based care; a strengthened community of provider-collaborators; and connections to vital support resources.

Looking ahead to stages 2 and 3 of meaningful use and beyond, practices planned to continue to re-engineer their practices to meet new requirements and new data demands; however, several practices expressed clear concern for the availability of EHRs that will be certified for stage 2meaningful use. As one physician asked, "How many EHRs will disappear because they can't meet stage 2 certification [requirements]?" It will not be easy for practices to change EHRs, pay for upgrades, and overcome technical issues without local and timely technical support.

Furthermore, while practices made significant progress in their re-engineering to adapt to new and ongoing changes, a key resource needed to facilitate ongoing changes are local advisors who help to sustain QI momentum in practices while sustaining vital local connections and collaboration among communities of providers and clinical practices.

Limitations for these analyses include the potential lack of generalizability of the sample, which consisted of small to intermediate-sized independent practices in a specific geographic region that agreed to participate in the CBC and may not be representative of other types of practices. Without comparison data from a larger sample of practices, we were unable to determine whether these results are unique to the CBC practices. Even within this sample of practices, experiences were quite variable. Other important barriers and resources may also exist.

Policies and incentive programs that continue to support community and regional resources that provide practices with direct, local EHR expertise, collaborative learning structures and venues, and practice QI advisors may be an efficient and necessary use of resources to sustain heath IT-based QI efforts in practices that are likely to face ongoing technical challenges. Further alignment of private sector strategies that complement Medicare and Medicaid meaningful use incentives could accelerate adoption and use of health IT. ${ }^{14}$ Without these resources, useful patient data may languish as providers and staff spend precious time to remedy technical barriers while implementing new or changed guidelines, programs, and improvements.

\section{Conclusions}

Meeting the stage 1 requirements for incentives under Medicare and Medicaid meaningful use is the first waypoint in a longer journey by primary care practices to meaningfully use their electronic patient data to continuously improve the care and 
health of their patients. The intensive re-engineering effort for stage 1 yielded practice changes that aligned with larger practice aims and goals. While many of these practices are now poised to meaningfully use data, faster progress will likely come with continued local QI and technical support and planned community-wide learning.

\section{References}

1. Blumenthal D, Tavenner M. The "meaningful use" regulation for electronic health records. $\mathrm{N}$ Engl J Med 2010;363:501-4.

2. Baron RJ. Meaningful use of health information technology is managing information. JAMA 2010; 304:89-90.

3. DesRoches CM, Campbell EG, Rao SR, et al. Electronic health records in ambulatory care-a national survey of physicians. N Engl J Med 2008;359:50-60.

4. Fernandopulle R, Patel N. How the electronic health record did not measure up to the demands of our medical home practice. Health Aff (Millwood) 2010;29:622-8.

5. Centers for Medicare and Medicaid Services (CMS), Department of Health and Human Services. Medicare and Medicaid Programs; electronic health record incentive program. Final rule. Fed Regist. 2010; 75:44313-588.

6. Hsiao C, Decker SL, Hing E, Sisk JE. Most physicians were eligible for federal incentives in 2011, but few had EHR systems that met meaningful-use criteria. Health Aff (Millwood) 2012;31:1100-7.

7. Police RL, Foster T, Wong KS. Adoption and use of health information technology in physician practice organisations: systematic review. Inform Prim Care 2011;18:245-58.
8. Rao SR, Desroches CM, Donelan K, Campbell EG, Miralles PD, Jha AK. Electronic health records in small physician practices: availability, use, and perceived benefits. J Am Med Inform Assoc 2011;18: 271-5.

9. Maxson E, Jain S, Kendall M, Mostashari F, Blumenthal D. The Regional Extension Center Program: helping physicians meaningfully use health information technology. Ann Intern Med 2010;153: $666-670$.

10. Office of the National Coordinator for Health Information Technology, Department of Health and Human Services. Health IT adoption programs: Beacon Community Program. Available from: http://www. healthit.gov/policy-researchers-implementers/beaconcommunity-program. Accessed December 19, 2012.

11. Office of the National Coordinator for Health Information Technology, Department of Health and Human Services. Health IT adoption programs: Beacon Community Program, Colorado Beacon Community (Grand Junction, CO). Available from: http://www.healthit.gov/ policy-researchers-implementers/colorado-beaconcommunity. Accessed December 19, 2012.

12. Miller WL, Crabtree BF. The dance of interpretation. In: Crabtree BF, Miller WL, eds. Doing qualitative research in primary care: multiple strategies. 2nd ed. Thousand Oaks, CA: Sage Publications; 1999:127-43.

13. Miles MB, Huberman AM, eds. Qualitative Data Analysis: A Sourcebook of New Methods. $2^{\text {nd }}$ ed. Thousand Oaks, CA: Sage Publications; 1994.

14. Jain SH, Seidman J, Blumenthal D. How health plans, health systems, and others in the private sector can stimulate "meaningful use". Health Aff (Millwood) 2010;29:1667-70. 


\section{APPENDIX 1: Data Collection Guides}

\section{Monthly Practice Narratives Questions}

[Practices responded to open-ended, structured prompts using a standardized template to answer the questions, updating the template monthly.]

- What was your best practice or innovative change this month as a result of your collaborative participation?

- What has been your biggest challenge to sustaining and spreading your work this month?

- What do you plan to do next month? Make a prediction about how your work will affect at least one key measure.

- Describe your tests of change (PDSAs) in each Care Model area, noting successive tests to refine your processes. Note which changes are actually implemented and have become adopted into your policies, procedures and daily routine. Note also your plan for and accomplished spread within your organization.

[Monthly detail provided description 1) description of PDSAs, 2) changes implemented, and 3) spread for each Care Model area: Delivery System Design, Decision Support, Clinical Information Systems, Self-Management Support, Community Linkages and Organization of a Health System].

\section{The Beacon Measures}

- For each of the following Beacon Measures [tobacco, blood pressure, BMI, etc.], please explain what your team has done and how you have used the information for practice improvement.

$\square$ We met or exceeded the Beacon Goal for this measure

We were unable to obtain any and/or valid data from an EMR or registry on this measure

- What internal data did you consider when deciding how to apply process improvement. (*Internal data are more than numbers out of your EMR/registry. Consider surveys (patient satisfaction, staff, etc.), phone calls, patient charts, word of mouth, patient cycle times.

- What specific process improvement techniques did your team utilize (team discussion, PDSA, process mapping, Learning Collaborative atten- dance, patient cycle times and other Webinar attendance)?

- What did your practice learn from your work on this measure?

- How does your practice plan to apply what you've learned going forward to continue practice transformation and improve patient outcomes regarding this measure?

- If your team was not able to address this measure please explain how you plan to address it in the future?

\section{QIA Interview Guide for Focus Group Discussion}

We are part of an evaluation team that is learning from the work that practices and you are doing to understand more about 1) meaningfully using EHR data for patient care and 2) patient engagement. Today we are specifically interested in getting your help to: describe the journey, struggles, successes, and barriers to obtain and use "meaningful use" data for quality improvement in primary care practices participating in the Colorado Beacon Consortium.

[Introductions]

\section{The Journey}

- What were your first impressions about some of the practices and their readiness for meaningfully using their patient data? What else did practices do early on to get started?

- We saw in the narratives a lot effort spent on changes to improve their ability to get better data. Some of this included new or changed office processes or patient flow.

$\circ$ How big of a deal are these practice changes? [Were they routine or really something new and different (in scope, time, cost, etc.)?]

- How does your work with practices support work flow changes?

- How do learning collaboratives help practices with MU progress?

- Is there a sense of community in this MU process among practices?

- These practices have described a lot of changes related to MU. A few of them mentioned the "strain" from all the changes or "fatigue."

$\circ$ How big of an issue is this? [Par for the course or MU is something different?] 
- Are practices managing for ongoing change, or just getting through an MU "project"?

- Looking ahead to Stage 2 of MU, how do you frame the process of Stage 1 and moving on to Stage 2?

- How do practices view the MU work they are doing: Staged mini-projects to get through versus a new way to provide care?

\section{Successes}

- What successes related to MU — of any kindcan you think of?

- Which do you think are the most important successes to highlight? Why these?

$\circ$ What else are practices doing with EHR MU data?

- How well does ability to report MU to CMS fit with ability to use data for patient care/practice improvement?

- Some practices appear to be truly using their data meaningfully for patient care and population management. What do you think contributes to their success?

- What other resources helped with using data meaningfully for patient care or practice improvement?

\section{Barriers}

- What barriers related to MU—of any kind—can you think of?

-Are there any "universal" barriers you've seen in most or all your practices?

- Change fatigue: How big of an issue is this? Par for the course or MU is something different? Are practices managing for ongoing change, or just getting through an MU "project"?

- Costs associated with MU appeared in the practice narratives. What other costs have we not considered or did not see in the Narratives?

- What other help does Beacon offer to practices to overcome barriers?

\section{Recommendations}

- What would you tell practices about where they should set their expectations when just getting started?
- What are the most important recommendations you have for practices trying to attain MU?

- What are the most important recommendations you have for practices trying to use their data meaningfully?

\section{Practice Provider/Staff Interviews for Semi- Structured Key Informant Interviews}

We are part of an evaluation team that is learning from the work that you are doing to understand more about 1) meaningfully using EHR data for patient care and 2) patient engagement. Today we are specifically interested in getting your help to: describe the journey, struggles, successes, and barriers to obtain and use "meaningful use" data for quality improvement in primary care practices participating in the Colorado Beacon Consortium.

[Introductions]

\section{The Journey}

- Take a moment and think back to what it was like when your practice first started getting ready to pursue "meaningful use." How did your practice get started on the journey?

$\circ$ How does this fit in with other practice improvement work you might be engaged in?

$\circ$ [Clinicians only] As a clinician, how did you prepare for meaningful use changes?

$\circ$ How did your practice prepare staff and administrators?

- How ready was your practice for this meaningful use journey? In what ways could you have prepared better in those early stages?

- We've heard and read a lot about some of the changes practices have made to achieve "meaningful use." How big of a deal are these practice changes? [Routine or really something new and different (in scope, time, cost, etc.)?]

$\checkmark$ How disruptive have these changes been that you described?

$\checkmark$ How beneficial for your practice overall have the changes been?

- What are some of the biggest barriers your practice has faced trying to achieve meaningful use? - Which of those barriers did your practice overcome? What are some barriers that have persisted? 
- What are your meaningful use successes? -What do you think has helped achieve those successes? What other resources can contribute to success?

\section{Meaningfully Using Data}

- We want to also think about other ways your practice uses data from its EHR meaningfully for patient care or practice improvement-think beyond the strict Medicare "meaningful use" criteria. In what ways does your practice really use its data for patient care?

$\circ$ What are you currently working on?

- What other ways are you thinking about using patient data in your practice?

- What have been some of your successes in uses data meaningfully?

- How much do you think this was influenced by "meaningful use" work? Or, to put it another way, how meaningful are "meaningful use" criteria for patient care?

- How has the Beacon group helped your practice to use data meaningfully?

- In what ways do Learning Collaboratives help your practice with meaningfully using data? Do you think there is a sense of community among practices in the Beacon area going through MU?

- What other resources have helped with using data meaningfully for patient care or practice improvement?

- What do you think primary care practices need to continue to use data meaningfully for patient care or practice improvement?

\section{Recommendations}

- What would you tell practices about where they should set their expectations when just getting started?
- What are the most important recommendations you have for practices trying to attain "MU"?

- What are the most important recommendations you have for practices trying to use their data meaningfully?

\section{Regional Extension Center (REC) Provider/ Staff Interviews for Group Discussion}

As you know, we are part of an evaluation team that is learning from the work that practices and you are doing to understand more about 1) meaningfully using EHR data for patient care and 2) patient engagement. We are specifically interested in getting your help to: further describe the journey, struggles, successes, and barriers to obtain and use "meaningful use" data for quality improvement in primary care practices participating in the Colorado Beacon Consortium.

[Introductions]

\section{Medicare "Meaningful Use"}

- We'd like to learn more about the specifics of how [the REC] works in an individual practice to help them achieve "meaningful use" for Medicare. How do you prepare practices?

$\circ$ What do you offer them?

- How well prepared are practices for using [the REC] for MU? Do practices have the technical resources they need (eg, computers, software, bandwidth)?

- What kinds of training is needed for providers and staff to use the health information exchange (HIE) for MU?

- From your perspective, what have been some of the challenges along the way to help practices achieve "meaningful use" for Medicare? How do these challenges arise?

- What are some of the successes, from your perspective?

-What do you think contributes to these successes?

- What are the most important lessons you've learned about HIEs and MU? 
- Who are the essential people to work with in a practice?

- How do you manage practice expectations for what [the REC] will do?

\section{Meaningfully Using Data}

- We'd also like to think beyond the technical requirements of MU public reporting for Medicare to how practices are meaningfully using their data for patient care. From your perspec- tive, what are some of the ways you see practices using [the REC resources] for patient care?

-What does it take for practices to really do this will (ie, use their patient data)?

- Thinking generally about HIEs, what do you think are the most important next steps that will help practices meaningfully use their data for patient care or population management? $\circ$ What resources (training, staffing, finances) do practices need to get there? What resources does [the REC] need to make this happen? 